\title{
Predicting organizational performance from motivation in Oromia Seed Enterprise Bale branch
}

\author{
Askalech Feyisa Jobira $^{1 凶}$ \& Abdulnasir Abdulmelike Mohammed (10 ${ }^{2}$
}

Motivation is one of the most researched yet crucial topics in academia from various perspectives. Despite this, researches show mixed results about the effect of extrinsic motivation on intrinsic motivation and organizational performance. Studies in Ethiopia also lack causal analysis and theoretical underpinning that made contributions from academia very little. Hence, this research is important to assess the effect of extrinsic motivation on intrinsic motivation and organizational performance from a cognitive evaluation theory perspective. The researchers adopted an explanatory research design with a quantitative approach. The entire 119 employees of the Oromia Seed Enterprise, Bale branch were included in the study to collect primary data through a close-ended questionnaire. The collected data was processed by SPSS software version 20. The relationship analysis was addressed by correlation and binary logistic regression analysis. Seen from extrinsic and intrinsic motivation aspects, the findings of the study showed that Oromia Seed Enterprise had a moderate level of organizational performance and a moderate level of employees' motivation. The correlation analysis result indicated that employees' extrinsic and intrinsic motivation had a positive relationship with organizational performance. The binary logistic regression analysis also indicated that extrinsic and intrinsic motivation had a positive and significant influence on organizational performance. However, the interaction effect of intrinsic and extrinsic motivation on organizational performance was not significant, implying the absence of influence when both intrinsic and extrinsic motivations happen at the same time. Finally, the study results have a theoretical contribution for compensating the lack of actual experience in the Ethiopian organization's context. Equally, the understanding of the moderated relationship among the study variables may encourage Oromia Seed Enterprise and its managers to develop a practical motivation system, which entertains the complex interaction of motivation variables to improve organizational performance. In addition, studies of this nature can inform policymakers to strengthen an incentive system as well as other motivation veins in the Ethiopian public organizations.

\footnotetext{
${ }^{1}$ Bale Zone Planning \& Economic Development Office, Bale Robe, Ethiopia. ${ }^{2}$ Madda Walabu University, Bale Robe, Ethiopia. ${ }^{凶}$ email: askufeye2745@gmail. com
} 


\section{Introduction}

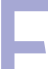
or organizations to perform better, it is imperative to get the most out of employees. To this end, the individual-level assessment of work motivation is essential. Work motivation has been the oldest and most researched topic in organizational psychology (see Maslow, 1943; Atkinson, 1958; Herzberg et al., 1959; Vroom, 1964; Locke, 1966; Deci, 1975; Fishbein and Ajzen, 1975; Hackman and Oldham, 1975; Bandura, 1977; Carver and Scheier, 1981; McClelland, 1985; Chen and Kanfer, 2006; Gagné et al., 2018). It touches the skills, jobs, and resource allocation strategies of individuals to influence activities in their organization (Kanfer et al., 2017). Motivation serves as a primary means to make employees work hard and become successful (Kanfer et al., 2017; Omollo and Oloko, 2015). It is a technique to elicit enthusiasm inside the employees so that they broaden their skills to meet the organizational demands. Hence, the presence of motivated employees amplifies the long-lasting success of organizations (Fallatah and Syed, 2017).

Because motivation is individualized, its agenda is customized to fit the needs and wants of the employees. Motivation has diverse manifestations, for instance, enhancing performance and demonstrating how good an organization cares. Perhaps the most vital impact of an employee's motivation is an increased productivity or performance (Steer, 1994; Grant, 2008; Sekhar et al., 2013; Cerasoli et al., 2014; Aderibigbe, 2017). Therefore, the central aim of adopting an employee motivational programs has been to increase employee motivation and productivity (Kanfer et al., 2017).

Employees make up the workforce of any organization; as such, they are an integral part of an organization. An organization composed of a group of people working collaboratively to achieve a common purpose (Christiana, 2018) highly depends on its employees to survive. Employee motivation stimulates workplace synchronization and better employee performance. It is the key to long-term benefits for the company, a means of staff retention, and a loyalty to a company (Němečková, 2017).

Several theories explain work motivation. For instance, a cognitive evaluation theory states that an intrinsic motivation leads people to satisfaction, whereas the introduction of an extrinsic incentive for people who need intrinsic motivation can have a negative effect (Cook and Artino, 2016). Intrinsic motivation arises from an employee's internal desire to execute a task out of self-interest rather than a need or wish for some external reward. Put in another way, intrinsic motivation considers the activity itself as a reward (Sullivan, 2019). Extrinsic motivation is the type of motivation that arises when an employee is forced either to act in a specific way because of that employee's desire for external rewards or to avoid punishment. Extrinsic motivation also helps boost an employee's effectiveness and efficiency levels. This is because certain external factors such as adequate compensation, work environment as well as training, and career development appeal to employees, and as such are essential in inspiring them to resourcefully discharge their duties (George and Jones, 2012; McShane and Von Glinow, 2018).

While many cognitive evaluation theories hypothesize extrinsic incentives undermine intrinsic motivation (Deci, 1975), the research results are mixed. According to Kanfer et al. (2017), a review of the last century studies on work motivation showed two categories of results: the ones supporting the undermining effect of an extrinsic incentive on intrinsic motivation, and the others that did not show the undermining effects.

Studies conducted in Ethiopia (like Mekonin, 2018; Assefa, 2018; Teshome, 2018; Zemene, 2013) focused on the effect of motivation on employees' performance. The commonality in those studies is their reliance on descriptive analysis without theoretical underpinning. Besides, those studies tried to see the direct and combined effect of motivation on organizational performance relying on descriptive statistics without splitting extrinsic and intrinsic motivation. However, this direct effect does not inform managers and other stakeholders about the reality on the ground. Additionally, studies of this nature (previous studies) did not clarify the question of whether or not there exists the undermining effect of an extrinsic motivation on intrinsic motivation in explaining organizational performance. One possible source of inability to address those questions is the usage of frequencies and percentages (despite the causal nature of the study titles). As such, studies with routine methodology and lack of theoretical underpinning reduce the quality of papers and it affects the contribution of academia in Ethiopia. By using binary logistic analysis, and basing its theoretical foundation in cognitive evaluation theory, this study, thus extends its analysis to cause-effect explanations. That is, to fill the above-mentioned gaps, this study aimed to assess the effect of extrinsic motivation on intrinsic motivation and organizational performance, from a cognitive evaluation theory perspective at the Oromia Seed Enterprise, Bale branch. This study also opens an avenue for future researchers to extend the methodology as well as include additional moderating variables on the current topic. To the literature, the study finding adds empirical value from an Ethiopian perspective.

\section{Research methodology}

The study employed an explanatory research design with a quantitative approach to address the cause-effect relationship among extrinsic motivation, intrinsic motivation and employees' performance. This is important because explanatory research designs have a power to explain cause-effect relationships. Moreover, the data generated from the data collection instrument are quantitative and as such approaching this study quantitatively is worth taking. To collect the data, a Likert scale close-ended questionnaire was used. Informed consents were obtained from the study participants prior to the distribution of the questionnaire.

The target population of this study consisted of employees and the management body of Bale branch Oromia Seed Enterprise. All participants (i.e., employees and management team) were included in the study (using a census/availability sampling technique). Therefore, the populations of the study were 12 supervisors, 77 professional experts, and 30 supporting staff totalling 119 respondents. The study used descriptive data analysis techniques (frequency, percentage and mean), correlation analysis, and binary logistic regression analysis.

Model specification for binary logistic regression. According to Gujarati (2004), the Logit model for the effect of employees' motivation on organizational performance is as follows:

$$
\begin{gathered}
P\left(Y_{i}=1\right)=\frac{1}{1+\mathrm{e}^{-\left(\beta_{\mathrm{i}} \mathrm{X}_{\mathrm{i}}\right)}} \\
P\left(Y_{i}=1\right)=\frac{1}{1+\mathrm{e}^{-Z_{i}}}
\end{gathered}
$$

where $P\left(Y_{i}=1\right)$ is the probability that the organization has a good performance, $Z_{i}$ is the function of a vector of explanatory variables, e- represents the base of natural logarithms and Eq. (2) is the cumulative employees' motivation function. If $P\left(Y_{i}=1\right)$ is the probability of the organization exhibiting a good performance, then $1-P\left(Y_{i}=0\right)$ represents the probability that the organization exhibits a poor performance is expressed as 
Table 1 Respondents age category by sex.

\begin{tabular}{|c|c|c|c|c|c|c|c|c|c|c|c|c|}
\hline \multirow[t]{2}{*}{ Age category } & \multicolumn{4}{|c|}{ Supervisor } & \multicolumn{4}{|c|}{ Professional expert } & \multicolumn{4}{|c|}{ Supportive staff } \\
\hline & $\mathbf{M}$ & $\mathbf{F}$ & Total & $\%$ & $\mathbf{M}$ & $\mathbf{F}$ & Total & $\%$ & $\mathbf{M}$ & $\mathbf{F}$ & Total & $\%$ \\
\hline $18-25$ & 0 & 0 & 0 & 0 & 6 & 5 & 11 & 15 & 1 & 0 & 1 & 3.5 \\
\hline $26-36$ & 2 & 0 & 2 & 40 & 16 & 14 & 30 & 41 & 13 & 6 & 19 & 67.8 \\
\hline $37-45$ & 1 & 1 & 2 & 40 & 10 & 8 & 18 & 24.6 & 5 & 0 & 5 & 17.8 \\
\hline$>45$ & 1 & 0 & 1 & 20 & 6 & 8 & 14 & 19.1 & 3 & 0 & 3 & 10.7 \\
\hline
\end{tabular}

$$
\begin{gathered}
1-P\left(Y_{i}=1\right)=1-\frac{1}{1+\mathrm{e}^{-Z_{\mathrm{i}}}}=\frac{1}{1+\mathrm{e}^{Z_{\mathrm{i}}}} \\
\frac{P\left(Y_{i}=1\right)}{1-P\left(Y_{i}=1\right)}=\frac{1+\mathrm{e}^{Z_{i}}}{1+\mathrm{e}^{-Z_{i}}}=\mathrm{e}^{Z_{i}}
\end{gathered}
$$

Equation (4) is the odds ratio, the ratio of the probability that the organization exhibits a good performance to the probability that the organization exhibits a poor performance. Taking the natural $\log$ of Eq. (4), we obtain

$$
L_{i}=\ln \left(\frac{P\left(Y_{i}=1\right)}{1-P\left(Y=1_{i}\right)}\right)=Z_{i}
$$

where $L_{i}$ is the log of the odds ratio introducing the stochastic error term $\left(U_{i}\right)$, the Logit model is written as

$$
Z_{i}=\beta_{0}+\beta_{1} X_{1}+\beta_{2} X_{2}+U_{i}
$$

where $X_{\mathrm{i}}$ 's are explanatory variables (intrinsic and extrinsic motivation) that affect the organizational performance, and $\beta_{0}$ is the constant term and $\beta_{i}$ 's are coefficients to be estimated.

\section{Results and discussion}

Background of the respondents. Of the 119 respondents, 106 (89\% response rate) of them completed and returned the questionnaires. The respondents' demographic information: sex, age, educational background, service year and workplace are described in Table 1. As such, $59.4 \%$ of the respondents were males and $40.6 \%$ of the respondents were females. Though the number of females in the Enterprise has envisaged a remarkable growth through time, their male counterparts still dominate the field.

More specifically, as depicted on Table 1, the dominant number of male supervisors $(80 \%)$ in the enterprise implies the presence of the traditional barriers that prohibit females from taking part in the supervision roles. These barriers may, however, be attributed to either female employees' perception of their capacity, or how others view them. At the professional experts' side, there is nearly an equivalent ratio of male and female employees. Overall, there is a dominance of male employees $(78 \%)$ over females in the enterprise.

Supervisors in the enterprise were composed of $40 \%$ employees aged from 18 to $36,40 \%$ aged from 37 to 45 , and $20 \%$ aged 45 and above. The implication here is that young employees occupy supervisory positions in the enterprise, making an enabling environment for exuberant and passionate management. Professional experts were mainly composed of $41 \%$ aged from 26 to 36 , and $24.6 \%$ aged from 37 to 45 . The remaining $19.1 \%$ and $15 \%$ aged $>45$, and between 18 and 25, respectively. Supportive staff were composed of $71.3 \%$ who aged from 18 to $36,17.8 \%$ aged from 37 to 45 , and $10.7 \%$ aged 45 and above.

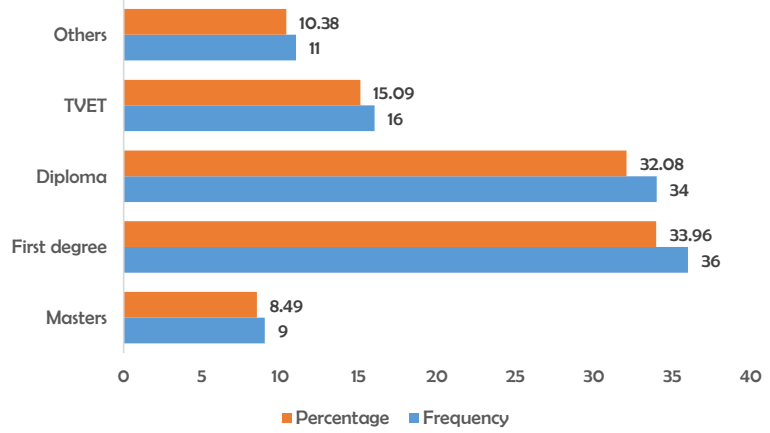

Fig. 1 Educational background of the respondents. Frequency and percentage of respondents' educational background.

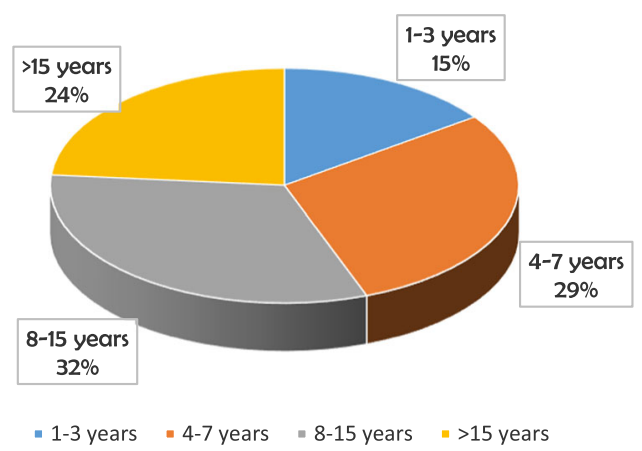

Fig. 2 Service years in the current organization. Percentage of respondents' service years in the current organization.

Educational background. Employees in the enterprise ought to have a minimum of a master's degree as per the guideline of the Ministry of Agriculture. However, the survey results in Fig. 1 revealed an insignificant percentage $(8.49 \%)$ of master's degree holders that denotes weak implementation capacity and lowcapacity building in the enterprise. The highest percentage goes to first-degree holders (33.96\%) followed by Diploma holders (32.08\%), TVET certificate holders (15.09\%) and below TVET certificates $(10.38 \%)$, respectively.

Respondents' years of service. Figure 2 shows a greater portion (32\%) of respondents falling in the service year range: $8-15$ years. This is followed by $29 \%$ of them who fall in the range of $4-7$ years, $24 \%$ of them more than 15 years, and $15 \%$ of the respondents' service year range between 1 and 3 years, respectively. This indicates that employees in the enterprise do stay at the post for a very long period which is important for the achievements of the mission and vision of the organization. 


\section{Table 2 Respondents view of extrinsic motivation.}

\begin{tabular}{llll} 
Sl. no. & Extrinsic motivation & Mean & Std. deviation \\
\hline 1 & The organization provides attractive salary & 2.58 \\
2 & The organization arranges job security & 2.46 & 0.567 \\
3 & The organization provides safety provision & 2.54 & 0.664 \\
4 & The organization arranges a good work environment & 2.38 & 0.620 \\
5 & The organization arranges a reward system & 2.13 & 0.696 \\
6 & The organization provides incentives and bonus & 2.46 & 0.663 \\
7 & The organization arranges promotion and career growth & 2.42 & 0.621 \\
8 & The organization arranges free medical service & 2.56 & 0.630 \\
9 & The organization provides fringe benefits & 2.45 & 0.634 \\
10 & The organization provides in house training & 2.10 & 0.649 \\
11 & Managements of the organization equally treat all employees & 2.27 & 0.703 \\
12 & The organization arranges compensation for employees & 2.20 & 0.737 \\
13 & The organization allow employees in decision making & 2.19 & 0.709 \\
& Mean & 2.36 & 0.692 \\
\hline
\end{tabular}

Table 3 Respondents view of intrinsic motivation.

\begin{tabular}{|c|c|c|c|}
\hline SI. no. & Intrinsic motivation & Mean & Std. deviation \\
\hline 1 & The organization provides Employees with an opportunity for achievement & 2.30 & 0.620 \\
\hline 2 & The organization provides Employees with a strong feeling of responsibility & 2.36 & 0.635 \\
\hline 3 & The organization provides Employees with challenging work & 2.42 & 0.632 \\
\hline 4 & The organization provides Employees with personal growth and development & 2.39 & 0.684 \\
\hline 5 & Employees are satisfied with their contribution to poverty reduction & 2.50 & 0.590 \\
\hline 6 & Employees are satisfied with low work pressure & 2.16 & 0.706 \\
\hline 7 & The organization provides Employees with opportunities to utilize their talents, abilities \& skills & 2.38 & 0.624 \\
\hline 8 & The organization provides Employees with opportunities to receive regular, timely feedback & 2.14 & 0.682 \\
\hline \multirow[t]{2}{*}{9} & Employees are committed to improving the quality of services regularly & 2.41 & 0.583 \\
\hline & Mean & 2.34 & 0.639 \\
\hline
\end{tabular}

Table 4 Correlation matrix.

\begin{tabular}{llll} 
& Organizational performance & Extrinsic motivation & Intrinsic motivation \\
\hline Organizational performance & 1 & 1 & $0.414^{\star \star}$ \\
Extrinsic motivation & $0.399^{\star \star}$ & & 1 \\
Intrinsic motivation & $0.418^{\star \star}$ & & \\
\hline${ }^{\star \star}$ Significant at $p<1 \%$. & & & \\
\hline
\end{tabular}

Extrinsic and intrinsic motivations. Work motivation largely depends on the craving to boost the effectiveness and efficiency in production. While researchers, for instance, Taylor (1911) relied on extrinsic rewards to motivate higher performance, other behavioural theorists focused on intrinsic rewards to boost performance (Kanfer et al., 2017). In Oromia Seed Enterprise, the researchers distributed a 13 -item questionnaire to measure the status of extrinsic motivation on a three-point scale. Based on the recommendation of Rushton et al. (1983) and Strube (2000), the study found a summated mean score of 2.36 (see Table 2) for extrinsic motivation. This score indicates the agreement of respondents on the presence of extrinsic motivation in Oromia Seed Enterprise. The other foil of motivation, intrinsic motivation, was measured using a 9-item questionnaire with three-point scale and returned a summated mean score of 2.34 (see Table 3 ). This score indicates the presence of intrinsic motivation in Oromia Seed Enterprise.

Organizational performance. An 8-item questionnaire was used to assess the current organizational performance. The responses collected from the five-point Likert scale were reduced to two categories. The most frequently responded ingredients of the organizational performance were customer satisfaction and profitability with a mean score of 3.71 and 3.91, respectively. Nonetheless, the least preferred response from the organizational performance ingredient was employee loyalty with a mean score of 3.49. Overall, the grand mean score of 3.62 indicates the agreement of respondents over the presence of good performance. At this point, one cannot predict organizational performance from employee motivation. However, a clear explanation of the relational and causal effect is presented in the topics hereunder.

Correlation analysis. Table 4 shows a positive relationship between organizational performance and employee motivation (both intrinsic and extrinsic). From this analysis, it is noted that extrinsic motivation is positively and moderately correlated $(r=0.399, p<0.01)$ with organizational performance. Added to this, intrinsic motivation is positively and moderately correlated $(r=0.418, p<0.01)$ with organizational performance.

Econometric results. Before conducting the binary logistic regression analysis, assumptions like multicollinearity, binary 
Table 5 Reliability test of variables.

\begin{tabular}{|lll|} 
Variables & $\begin{array}{l}\text { Number } \\
\text { of items }\end{array}$ & $\begin{array}{l}\text { Cronbach's } \\
\text { alpha value }\end{array}$ \\
\hline Extrinsic motivation & 13 & 0.751 \\
Intrinsic motivation & 9 & 0.701 \\
Organizational performance & 8 & 0.715 \\
\hline
\end{tabular}

\begin{tabular}{|c|c|c|c|c|}
\hline $\begin{array}{l}\text { Variables in the } \\
\text { equation }\end{array}$ & Coefficient & Standard error & $p$ & $\begin{array}{l}\text { Odds } \\
\text { ratio (OR) }\end{array}$ \\
\hline Extmotiv & & & 0.064 & \\
\hline Extmotiv(1) & -2.862 & 1.222 & 0.019 & 0.057 \\
\hline Extmotiv(2) & -19.593 & $1.421 \mathrm{E} 4$ & 0.999 & 0.000 \\
\hline Intmotiv & & & 0.087 & \\
\hline Intmotiv(1) & -3.401 & 1.538 & 0.027 & 0.033 \\
\hline Intmotiv(2) & -19.257 & $1.421 \mathrm{E} 4$ & 0.999 & 0.000 \\
\hline Extmotiv Intmotiv & & & 1.000 & \\
\hline $\begin{array}{l}\text { Extmotiv(1) by } \\
\operatorname{Intmotiv(1)}\end{array}$ & -36.142 & 2.461E4 & 0.999 & 0.000 \\
\hline $\begin{array}{l}\operatorname{Extmotiv}(2) \text { by } \\
\text { Intmotiv(2) }\end{array}$ & 17.128 & $1.421 \mathrm{E} 4$ & 0.999 & $2.744 \mathrm{E} 7$ \\
\hline Constant & 21.203 & $1.421 \mathrm{E} 4$ & 0.999 & 1.615E9 \\
\hline
\end{tabular}

avariable(s) entered on step 1: extmotiv, intmotiv, extmotiv ${ }^{\star}$ intmotiv.

Disagree is the reference category.

outcome variable, residuals and outliers were checked against the standards. Hence, the correlation matrix did not show a high correlation among the explanatory variables. Similarly, the outcome variable yielded binary responses that were recoded as poor (0) and good (1) organizational performance. Cook's distance and DF Beta were less than unity meeting the criteria. Finally, yet importantly, outliers were not seen in the data at hand. The variables were also found to be reliable, scoring $>0.7$ as recommended by Muijs (2004). Table 5 describes Cronbach's alpha value of the variables.

Speaking of the model fitness, $72.6 \%$ of the cases were correctly classified with the Hosmer and Lemeshow test being 0.983 , which is not statistically significant and therefore the model has a good fit. Besides, $36.5 \%$ of the variation in the organizational performance was as the result of intrinsic and extrinsic motivation.

Results from Table 6 ascertain the possibility of predicting organizational performance significantly from both intrinsic and extrinsic motivations. The odds of the organization for poorly performing is much lower $(\mathrm{OR}=0.057, p<0.05)$ among employees who moderately agree on the presence of extrinsic motivation compared to those who disagree with the presence of extrinsic motivation. Similarly, the odds of the organization for poorly performing is much lower $(\mathrm{OR}=0.033, p<0.05)$ for those employees who moderately agree on the presence of intrinsic motivation compared to those who disagree with the presence of extrinsic motivation. The implication here is those employees who perceived the presence of moderate motivation (intrinsic and extrinsic) were less likely to contribute to poor organizational performance. The ability of intrinsic and extrinsic motivation to predict organizational performance, as evidenced in the moderate sense of the above results, was congruent with the results of (Zemene, 2013; Rizwan, 2001; Maurer, 2001). The results were also partially congruent with Lin (2007) where one of the motivations (intrinsic or extrinsic) aspects were significant predictors of organizational performance.

The study also checked for the interaction effect of intrinsic and extrinsic motivations on organizational performance. The result from Table 6 indicates such an interaction does not have a significant interplaying effect on organizational performance. However, the intrinsic and extrinsic motivations, as the main effect, had a significant effect on organizational performance. This by itself is an indication of the absence of the moderating effect of extrinsic motivation on the relationship between intrinsic motivation and organizational performance. Thus, our finding failed to prove the proposition of Deci (1975) and adds support to the work and results of other researchers (see Eisenberger et al., 1999; Cameron and Pierce, 1994; Phillips and Lord, 1980) who found no undermining effect of extrinsic motivation on intrinsic motivation.

\section{Conclusion and discussion}

This research aimed to assess the effect of extrinsic motivation on intrinsic motivation and organizational performance from cognitive evaluation theory perspective. For this purpose, we relied on explanatory research design, took all employees in the enterprise and collected responses through questionnaires from 106 respondents. Accordingly, the following conclusions and discussions were obtained.

Research conclusions. The descriptive statistics show the majority of the respondents were male. Besides, the majority of the respondents were aged 26-36. First-degree holders took the lion's share, followed by diploma, certificate, TVET and master degree holders in the enterprise. The service year of the respondents include $8-15$ years (32\%), 4-7 years (29\%), more than 15 years $(24 \%)$, and $1-3$ years $(15 \%)$, respectively. The result also shows the agreement of respondents on the presence of extrinsic and intrinsic motivations in the enterprise. The econometric results show that those employees who perceived the presence of moderate motivation (intrinsic and extrinsic) were less likely to contribute to poor organizational performance. The study also checked for the interaction effect of intrinsic and extrinsic motivation on organizational performance and indicated an insignificant interplaying effect on organizational performance.

Research contributions. This study draws attention to the effect of extrinsic motivation on intrinsic motivation and organizational performance in the Oromia Seed enterprise context. The results have significant contributions to researchers, the existing theory, practice, and policymakers. First, despite the maturity of the field and presence of research on the relationships between motivation and organizational performance, still, empirical studies looking at the interaction effect of intrinsic and extrinsic motivations need to be conducted in the Ethiopian context. Second, results from this study support the existing proposition that extrinsic motivation does not have a significant effect on intrinsic motivation and resulting organizational performance. Hence, the study results have a theoretical contribution for compensating the lack of actual experience in the Ethiopian organization's context. Third, the understanding of the moderated relationship among the study variables will encourage Oromia Seed Enterprise and its managers to develop a practical motivation system, which entertains the complex interaction of motivation variables, to improve organizational performance. Finally, this study specifically focused on the Seed Enterprise, Bale Branch, and insights into the enterprise's perceived motivation (extrinsic and 
intrinsic), as well as organizational performance, may also be of interest to other branches in the Oromia Region. In addition, studies of this nature can inform policymakers to strengthen the incentive system as well as other motivation veins in the Ethiopian public organizations.

Limitations and future research. Assessing the effect of extrinsic motivation on intrinsic motivation and organizational performance through explanatory research has its values. However, we acknowledge a few limitations of this study to be improved. First, this study focused only on extrinsic and intrinsic motivations as well as their interaction effect on organizational performance. In doing so, our ability to see the moderating effect of other variables that are outside the scope of this study is limited. Besides, the usage of binary logistic regression may limit the ability to see complex relationships among the study variables. Future studies can extend this study by adding other relevant moderating variables, for instance, autonomy, to examine the moderating role of autonomy in the relationship between motivation (extrinsic and intrinsic) and organizational performance so that they can further extend our understanding of motivation from the cognitive evaluation theory perspective. It is also worth considering (for future studies) to use structural equation modelling to uncover complex relationships among the study variables. Second, this study is cross-sectional in nature that does not consider the effect over a long period. As such, the cause-effect relationship of the study variables can only be representative of one point at a time. Thus, future studies can extend the research design into longitudinal and look into the effect of extrinsic motivation on intrinsic motivation and organizational performance across multiple times. Third, this study did not cover all Seed Enterprises in Ethiopia due to budgetary limitations. Though the study achieved its objectives, its results cannot be generalized to all enterprises in Ethiopia. Hence, future studies can extend the research to cover more enterprises across Ethiopia.

\section{Data availability}

The quantitative data analysed in the current study are not publicly available due to confidentiality reasons, but are available from the corresponding author on reasonable request.

Received: 3 March 2020; Accepted: 10 February 2021;

Published online: 08 March 2021

\section{References}

Aderibigbe IAI (2017) Relationship between employee motivation and productivity among bankers in Nigeria. J Econ 8(1):76-80

Assefa H (2018) Impact of motivation on employee's performance: case study in Bank of Abyssinia selected Addis Ababa branches. Dissertation, St. Mary's University

Atkinson JW (1958) Towards experimental analysis of human motivation in terms of motives, expectancies, and incentives. In: Atkinson JW (ed) Motives in fantasy, action and society. Van Nostrand, New York, pp. 288-305

Bandura A (1977) Self-efficacy: toward a unifying theory of behavioural change. Psychol Rev 84:191-215

Cameron J, Pierce WD (1994) Reinforcement, reward, and intrinsic motivation: a meta-analysis. Rev Educ Res 64(3):363-423

Carver CS, Scheier MF (1981) Attention and self-regulation: a control-theory approach to human behaviour. Springer Verlag, New York

Cerasoli CP, Nicklin JM, Ford MT (2014) Intrinsic motivation and extrinsic incentives jointly predict performance: a 40-year meta-analysis. Psychol Bull 140:980-1008

Chen G, Kanfer R (2006) Toward a systems theory of motivated behaviour in work teams. Res Organ Behav 27:223-267

Christiana MBV (2018) Organizational behaviour. Educreation Publishing

Cook DA, Artino Jr AR (2016) Motivation to learn: an overview of contemporary theories. Med Educ 50(10):997-114

Deci EL (1975) Intrinsic motivation. New York and London. Plenum Press
Eisenberger R, Pierce WD, Cameron J (1999) Effects of reward on intrinsic motivation-negative, neutral, and positive: comment on Deci, Koestner, and Ryan. Psychological Bulletin, 125(6):677-691. The American Psychological Association

Fallatah RHM, Syed J (2017) Employee motivation in Saudi Arabia: an investigation into the higher education sector. Springer

Fishbein M, Ajzen I (1975) Belief, attitude, intention, and behaviour: an introduction to theory and research. Addison Wesley, Reading

Gagné M, Deci EL, Ryan RM (2018) Self-determination theory applied to work motivation and organizational behaviour. In: Ones DS, Anderson N, Viswesvaran C, Sinangli HK (eds) The SAGE handbook of industrial, work \& organizational psychology: organizational psychology. pp. 97-121. SAGE

George JM, Jones GR (2012) Understanding and managing organizational behaviour, 6th edn. Prentice Hall, Reading

Grant AM (2008) Does intrinsic motivation fuel the prosocial fire? Motivational synergy in predicting persistence, performance, and productivity. J Appl Psychol 93:48-58

Gujarati DN (2004) Basic econometrics, 4th edn. The McGraw-Hill Companies

Hackman JR, Oldham GR (1975) Development of the job diagnostic survey. J Appl Psychol 60:159-170

Herzberg F, Mausner B, Snyderman BB (1959) The motivation to work, 2nd edn. Wiley, New York

Kanfer R, Frese M, Johnson RE (2017) Motivation related to work: a century of progress. J Appl Psychol 102(3):338

Lin HF (2007) Effects of extrinsic and intrinsic motivation on employee knowledge sharing intentions. J Inf Sci 33(2):135-149

Locke EA (1966) The relationship of intentions to level of performance. J Appl Psychol 50:60-66

Maslow AH (1943) A theory of human motivation. Psychol Rev 50:370-396

Maurer TJ (2001) Career-relevant learning and development, worker age, and beliefs about self-efficacy for development. J Manag 27(2):123-140

McClelland DC (1985) Human motivation. Cambridge University Press, Cambridge

McShane SL, Von Glinow MA (2018) Organizational behaviour. McGraw-Hill Education, New York

Mekonnen HG (2018) Effect of motivation on employees performance: the case of Commercial Bank of Ethiopia-North Addis Ababa District. Dissertation, Debre Berhan University

Muijs D (2004) Doing quantitative research in education with SPSS. Sage Publications Ltd., London

Němečková I (2017) The role of benefits in employee motivation and retention in the financial sector of the Czech Republic. Econ Res-Ekonom istraž 30 (1):694-704

Omollo PA, Oloko MA (2015) Effect of motivation on employee performance of commercial Banks in Kenya: a case study of Kenya Commercial Bank in Migori County. Int J Hum Resource Stud 5(2):87-103

Phillips JS, Lord RG (1980) Determinants of intrinsic motivation: locus of control and competence information as components of Deci's cognitive evaluation theory. J Appl Psychol 65(2):211

Rizwan (2001) Impact of employees motivation on organizational effectiveness Dissertation, The Islamia University of Bahawalpur

Rushton JP, Brainerd CJ, Pressley M (1983) Behavioural development and construct validity: the principle of aggregation. Psychol Bull 94(1):18

Sekhar C, Patwardhan M, Singh RK (2013) A literature review on motivation. Global Bus Perspect 1(4):471-487

Steer RM (1994) Introduction to organizational behaviour. Harper Collins Publisher, New York

Strube MJ (2000) Reliability and generalizability theory. In: Grimm LG, Yarnold PR (eds) Reading and understanding MORE multivariate statistics pp. 23-66. The American Psychological Association

Sullivan GS (2019) SDT mini-theories: basic psychological need satisfaction, intrinsic motivation, and cognitive evaluation. In: Dhiman S, Roberts G, Crossman J (eds) Servant leadership in sport. Palgrave Macmillan, Cham, pp. 219-227

Taylor FW (1911) The principles of scientific management. Harper \& Brothers, New York

Teshome A (2018) Effects of motivation on employee performance in public enterprise: in the case of Ethiopian shipping and logistics services enterprise. Dissertation, Addis Ababa University

Vroom VH (1964) Work and motivation. Wiley, New York

Zemene F (2013) The effects of motivation on employees' performance at Mekdim Ethiopia National Association. Dissertation, St. Mary's University

\section{Acknowledgements}

The researchers would like to thank Mr. Atota Bedane Halkiyo for his professional language editing support. 


\section{Author contributions}

The authors contributed equally to this work.

\section{Ethical approval}

This research was conducted with the approval and supervision of Madda Walabu University Research Ethics Review Committee (No. 0006/2013) regarding ethical issues in the whole research process.

\section{Competing interests}

The authors declare no competing interests.

\section{Additional information}

Correspondence and requests for materials should be addressed to A.F.J.

Reprints and permission information is available at http://www.nature.com/reprints
Publisher's note Springer Nature remains neutral with regard to jurisdictional claims in published maps and institutional affiliations.

cC (i) Open Access This article is licensed under a Creative Commons Attribution 4.0 International License, which permits use, sharing, adaptation, distribution and reproduction in any medium or format, as long as you give appropriate credit to the original author(s) and the source, provide a link to the Creative Commons license, and indicate if changes were made. The images or other third party material in this article are included in the article's Creative Commons license, unless indicated otherwise in a credit line to the material. If material is not included in the article's Creative Commons license and your intended use is not permitted by statutory regulation or exceeds the permitted use, you will need to obtain permission directly from the copyright holder. To view a copy of this license, visit http://creativecommons.org/licenses/by/4.0/.

(C) The Author(s) 2021 